\title{
The Impact of Health Policy on Patients' Awareness of the Risks Associated with Obesity: An International Multicenter Study in Poland and Germany
}

\author{
Anna Paczkowska $\mathbb{D}^{1}$, Karolina Hoffmann ${ }^{2}$, Jonas Raakow ${ }^{3}$, Matthias Pross ${ }^{4}$, Rafael Berghaus ${ }^{4}$, \\ Michał Michalak $\mathbb{D}^{5}$, Wiesław Bryl $\mathbb{D}^{2}$, Kinga Marzec', Dorota Kopciuch', Tomasz Zaprutko', \\ Piotr Ratajczak', Elżbieta Nowakowska ${ }^{6}$, Krzysztof Kus ${ }^{1}$ \\ 'Department of Pharmacoeconomics and Social Pharmacy, Poznan University of Medical Sciences, Poznan, Poland; ${ }^{2}$ Department of Internal Diseases, \\ Metabolic Disorders and Arterial Hypertension, Poznan University of Medical Sciences, Poznan, Poland; ${ }^{3}$ Department of Surgery, Campus Charité \\ Mitte and Campus Virchow Klinikum, Charité - Universitätsmedizin Berlin, Berlin, I0I 17, Germany; ${ }^{4}$ Department of Surgery, DRK Kliniken Berlin, \\ Köpenick, Berlin, 12559, Germany; ${ }^{5}$ Department of Computer Science and Statistics, Poznan University of Medical Sciences, Poznan, Poland; \\ ${ }^{6}$ Department of Pharmacology and Toxicology Institute of Health Sciences, Collegium Medicum, University of Zielona Gora, Zielona Góra, Poland \\ Correspondence: Anna Paczkowska, Department of Pharmacoeconomics and Social Pharmacy, Poznan University of Medical Sciences, Rokietnicka 7 Street, \\ Poznan, 60-806, Poland, Tel +48 507975 635, Fax +48 6I8546894, Email aniapaczkowska@ump.edu.pl
}

\begin{abstract}
Background: Recent studies indicate that the treatment of obesity is unsuccessful. The cause of this situation is that patients are not sufficiently educated about therapeutic methods and the health consequences of not treating obesity. Moreover, obesity prevention strategies differ significantly between EU countries.

Objective: The primary aim of this study was to examine and compare the level of obesity-related knowledge and illness perception among obese patients from Poland and Germany.

Methods: A prospective cross-sectional international multicentre study was conducted. The study included 564 subjects above 18 years old (210 German patients and 354 Polish patients) with obesity. A validated custom-made questionnaire was used to evaluate obesity-related knowledge. Patient illness perception was evaluated using Polish and German language versions of the standardized Brief Illness Perception Questionnaire (B-IPQ).

Results: Obese patients from Germany had significantly higher level of obesity-related knowledge than patients from Poland (22.01 \pm 4.68 vs $19.17 \pm 6.59, \mathrm{p}<0.0001)$. Obesity-related knowledge was associated with the patient's education, patient participation in therapeutic educational programs, patient's perception of the illness, age and the number of healthcare professionals involved in the patient's treatment process.

Conclusion: The level of obesity-related knowledge among both Polish and German patients is unsatisfactory. This study suggests that health education is required to facilitate informed choices and support the use of cognitive approaches educating patients on the health consequences of obesity.
\end{abstract}

Keywords: obesity, patient education, health education, health behaviour, illness perception

\section{Introduction}

According to the World Health Organization (WHO), both overweight and obesity are abnormal or excessive fat accumulation, which is a risk to health. In the definition a body mass index (BMI) is used, which helps to describe a person as an overweight if BMI is over $25 \mathrm{~kg} / \mathrm{m}^{2}$, and as an obese if it is over $30 \mathrm{~kg} / \mathrm{m}^{2}{ }^{1}$

The prevalence of obesity worldwide, including in the European Union (EU) countries, is currently considered one of the major public health problems. ${ }^{2-4}$ Obesity has been described by the WHO as an important risk factor for numerous diseases, including glucose and lipid disorders, some types of neoplasm, atherosclerosis and its consequences, eg, coronary artery disease, arterial hypertension, hyperlipidemia, and stroke ${ }^{5,6}$ Recent studies indicate that the most common cause of unsuccessful morbid obesity treatment is a lack of cooperation between patients and physicians within 
the scope of compliance with behavior therapy. This has been caused by patients' insufficient education on the therapeutic methods and the health consequences of not treating obesity. "Perception" seems to be a significant determinant of pro-health behavior or activities. ${ }^{8}$ Studies have shown that the number of weight loss attempts increases as the perceived susceptibility to chronic disease increases. It must be emphasized that those obese individuals who are more prone to fight overweight are usually well-educated in the field of obesity and its health consequences. ${ }^{9,10}$

According to the Health Belief Model, perception and awareness of obesity as a risk factor for many diseases is crucial for health behavior change. ${ }^{11,12}$ Numerous interventions against obesity, both individual and population-level, focused on increasing the patient's knowledge concerning the disease, the patient's attitudes and perception of the problem, are concentrated on lifestyle modification, including diet and physical activity. For example, in Germany, public money supports a national health promotion campaign to increase fruit and vegetable consumption and increase physical activity. Moreover, obesity prevention strategies differ significantly between EU countries. As an example, the German government allocates much more financial resources to implement therapeutic, educational programs in obesity than the Polish government. ${ }^{13}$

So far, scarcely is known on the comparison of the level of knowledge and perception of obesity among patients treated in selected EU countries.

Moreover, a limited number of studies have reported a relationship between patients' obesity- related knowledge and illness perception. ${ }^{14}$

Therefore, the primary aim of this study was to examine and compare the level of knowledge about prevention, treatment methods and health consequences of obesity, and the perception of the illness among obese patients from Poland and Germany. The additional aim was to estimate demographic and clinical factors associated with obesity-related knowledge. The relationship between obesity-related knowledge and participation in a therapeutic education program was also examined.

\section{Materials and Methods Study Population}

A prospective cross-sectional international multicentre study was conducted at selected health care facilities in Germany and in Poland. Data were collated prospectively from 564 consecutive patients in 4 international centers. Two health care facilities from each country was involved in the data collection process. The target group consisted of 564 patients (354 from Poland-PL and 210 from Germany-DE) above 18 years old, with diagnosed and treated obesity in the time horizon $1 / 2018$ and 12/2019. The inclusion criteria for both groups were as follows: BMI $\geq 30 \mathrm{~kg} / \mathrm{m}^{2}$ with obesity-related comorbidity, age $\geq 18$ years, and the ability to understand and comply with the study procedures. The attending physician decided to include every single patient in the study. All the recruited subjects were fully informed about study goals and conditions. Before the survey, they gave written informed consent to participate in the project. The Ethics Committee of the Poznan University of Medical Sciences and the Charite - Universitätsmedizin Berlin approved the study protocol.

\section{Study Technique}

A custom-made questionnaire based on the literature related to this issue was used to evaluate obesity-related knowledge. ${ }^{11,15}$ The questionnaire comprised 46 closed questions related to the level of patients' knowledge regarding therapeutic options, prevention, risk factors, and complications of obesity. Additionally, the questionnaire included inquiries related to awareness and participation in education programs in obesity and behavior therapy conducted by physicians or nurses. The study questionnaire was accepted by the group of five national Medical consultants in the field of obesity (three from Germany and two from Poland). In order to evaluate the psychometric properties of German and Polish versions of the questionnaire, it was pre-tested on a sample of 150 obese patients (representative sample: 75 German and 75 Poles) who had the purpose of the study explained to them. Subsequently, the questions could be revised if needed. The results of the pre-test were included in the final study since the pre-test did not yield any major modifications of the instrument. Internal consistency of the obesity-related questionnaire is, the extent to which the items are correlated - was determined by calculating Cronbach's $\alpha$. A good internal consistency $(0.7 \leq \alpha \leq 0.9)$ can be seen 
as a precondition of the fact that the summation of the single item scores to a total score is meaningful. ${ }^{16}$ Cronbach's $\alpha$ was 0.82 and 0.84 for the total score among German and Polish patients, respectively.

Respondents were awarded one point for every correct response. A given patent's overall score reflected how much they knew about obesity. A scoring system was adopted wherein scores of 23-28, 29-37, 38-46 were attributed to low, average and high levels of obesity knowledge, respectively.

Moreover, from medical records there were collected information concerning on a range of variables, including details on course of obesity, such as disease duration, current body mass index, type of bariatric Surgery performed, time elapsed since bariatric surgery, types of intervention and application areas as part of conservative treatment of morbid obesity, duration or presence of comorbid diseases. The patient's illness perception was evaluated using Polish and German versions of the standardized Brief Illness Perception Questionnaire (B-IPQ). ${ }^{17,18}$ The B-IPQ consists of nine items rated on a scale from 0 (minimum) to 10 (maximum). With the Brief IPQ, it is possible to estimate illness perception in large-scale projects and repeated measures study designs. Scores reflected the disease severity scale or how relaxed the person was concerned about the disease. The higher the score, the more a person feels threatened by the illness. ${ }^{19}$

\section{Statistical Analysis}

The quantitative parameters were presented using mean value, median, and standard deviation. Categorical data were presented as counts and percentages. Results obtained for individual study groups were compared using the Student's $t$-test. A comparison was performed using the Mann-Whitney test, where data did not follow the normal distribution (the Shapiro-Wilks test). More than two groups were compared using the Kruskal-Wallis test with the post hoc Dunn's test. The Chi-square test for independence was used to analyze categorical data.

The relationship between the knowledge level and study parameters was analysed using multiple regression analysis. For categorical data, the coefficient for a specified level was compared to the reference level.

The analysis was performed with the use of the TIBCO Software Inc. (2017) statistical package. Statistica (data analysis software, TIBCO Software Inc., Palo Alto, USA, ver. $13.3 \mathrm{http}: / /$ statistica.io. All tests were considered significant for $\mathrm{p}<0.05$.

\section{Results}

\section{Characteristics of the Study Group}

The socio-demographic characteristics of the sample are shown in Table 1. The study group included 564 patients (354 from Poland and 210 from Germany), aged 45.20 \pm 15.69- PL and 45.70 \pm 9.70- DE with diagnosed and treated obesity. In both groups, the majority of patients were female $-77.40 \%$ - PL and $75.24 \%$ - DE. The studied groups did not statistically differ in terms of gender, age, body mass index, degree of obesity, duration of the disease and level of education ( $\mathrm{p}>0.05)$.

\section{Obesity-Related Knowledge Assessment}

According to our comparative analysis of the patient's obesity knowledge level based on the Mann-Whitney $U$-test, obese patients from Poland had much worse obesity-related knowledge than those from Germany (19.17 \pm 6.59 - PL vs $22.01 \pm 4.68$ $\mathrm{DE}, \mathrm{p}<0.0001)$ (Table 2). Patients with a low level of obesity knowledge were in the majority in both countries $(94.07 \%$ PL vs $93.81 \% \mathrm{DE}, \mathrm{p}=0.683)$. On the other hand, there were significantly less patients with a high level of obesity knowledge in the group of Polish subjects compared to the German ones $(0.00 \%$ PL vs $1.90 \% \mathrm{DE}, \mathrm{p}=0.024)$.

Both in the German and Polish groups, participation in a specialist obesity-related educational program significantly contributed to the improvement of knowledge about obesity. Among patients participating in educational programs, the percentage of subjects with medium and high level of knowledge was significantly higher than in the group not participating in the educational program $(\mathrm{p}<0.0001)$ (Table 2). Only $7.06 \%$ of the patients from Poland and $18.57 \%$ of the patients from Germany attended a specialist education program supporting a national health promotion campaign against obesity. The most popular educational programs within the scope of obesity prevention and treatment methods, which the surveyed German patients took part in, were as follows: MMK (in German: Multimodales Therapiekonzept; in English: Concept of Multimodal Therapy) (27.27\%), AOK (in German: Allgemeine Ortskrankenkasse; in English: 
Table I Socio-Demographic and Somatic Differences Between Obese Patients from Poland and Germany $(n=564)$

\begin{tabular}{|c|c|c|c|c|}
\hline & & Poland & Germany & p value \\
\hline \multirow[t]{5}{*}{ Group size } & Total & 354 & 210 & \\
\hline & Female \% & 77.40 & 75.24 & 0.7563 \\
\hline & Male \% & 22.60 & 24.76 & \multirow[t]{3}{*}{0.5369} \\
\hline & Surgically treated patients n (\%) & $82(23.16)$ & $73(34.76)$ & \\
\hline & Conservatively treated patients $\mathrm{n}(\%)$ & $272(76.84)$ & I $37(65.24)$ & \\
\hline Age (years) & Mean \pm SD & $45.20 \pm 15.69$ & $45.70 \pm 9.70$ & 0.8541 \\
\hline Body mass index - BMI $\left(\mathrm{kg} / \mathrm{m}^{2}\right)$ & Mean \pm SD & $36.92 \pm 8.12$ & $36.87 \pm 10.06$ & 0.9452 \\
\hline I degree of obesity BMI $\geq 30-34.9 \mathrm{~kg} / \mathrm{m}^{2}$ & $\%$ & 27.96 & 27.14 & 0.8876 \\
\hline II degree of obesity BMI $\geq 35-39.9 \mathrm{~kg} / \mathrm{m}^{2}$ & $\%$ & 29.66 & 25.10 & 0.0681 \\
\hline III degree of obesity BMI $\geq 40\left(\mathrm{~kg} / \mathrm{m}^{2}\right.$ & $\%$ & 42.38 & 47.76 & 0.0741 \\
\hline Duration of the obesity (years) & Mean \pm SD & $17.67 \pm|1.6|$ & $17.00 \pm 10.5 \mid$ & 0.7561 \\
\hline \multirow[t]{4}{*}{ Education } & Primary (\%) & 8.44 & 3.71 & 0.0953 \\
\hline & Vocational (\%) & 28.00 & 33.00 & 0.1641 \\
\hline & Secondary (\%) & 42.66 & 41.06 & 0.7452 \\
\hline & Higher (\%) & 20.90 & 22.23 & 0.1237 \\
\hline \multirow[t]{5}{*}{ Financial situation } & Definitely good (\%) (income per month: >3000 EUR) & 10.20 & 10.50 & 0.9456 \\
\hline & Good (\%) (income per month: 200I-3000 EUR) & 34.36 & 35.66 & 0.5632 \\
\hline & Average (\%) (income per month: I00I-2000 EUR) & 43.62 & 44.16 & 0.6569 \\
\hline & Bad (\%) (income per month: 500-1000 EUR) & 7.63 & 7.11 & 0.8962 \\
\hline & Definitely bad (\%) (income per month: $<500$ EUR) & 4.19 & 2.57 & 0.0956 \\
\hline \multirow[t]{6}{*}{ Comorbidities } & Type 2 diabetes mellitus (\%) & 27.11 & 28.57 & 0.4589 \\
\hline & Hypertension (\%) & 45.48 & 47.61 & 0.1253 \\
\hline & Dyslipidemia (\%) & 17.79 & 19.04 & 0.1478 \\
\hline & Hyperuricemia (\%) & 3.95 & 5.71 & 0.0635 \\
\hline & Metabolic syndrome (\%) & 13.56 & 16.66 & 0.0856 \\
\hline & Coronary artery disease (\%) & 24.85 & 24.76 & 0.7563 \\
\hline
\end{tabular}

Abbreviation: SD, standard deviation.

General regional health insurance) (18.18\%), Obesity Balance (18.18\%), Weight Watchers (18.18\%), Moby Dick $(9.09 \%)$ and Optifast $(9.09 \%)$. In Poland, the most popular educational programs within the scope of obesity prevention and treatment methods the surveyed participants took part in were as follows: Fit2Be $(60 \%)$ and Dare to be healthier - let us fight obesity! (40\%).

\section{Illness Perception Assessment}

Using the Mann-Whitney $U$-test it was shown that from the patient's perspective, the surveyed Polish group exhibited a significantly higher obesity perception level than the German one $(43.33 \pm 12.17$-PL vs $37.98 \pm 17.23$ $\mathrm{DE}, \mathrm{p}<0.0001$ ) (Table 3). Additionally, the study showed that in both groups, the level of disease perception 
Table 2 Assessment of the Obesity-Related Knowledge Depending on the Attended at Therapeutic Education Program Against Obesity in the Group of Obese Patients from Poland and Germany $(n=564)$

\begin{tabular}{|c|c|c|c|c|c|c|}
\hline \multirow{2}{*}{$\begin{array}{l}\text { Level of } \\
\text { Knowledge }\end{array}$} & \multicolumn{3}{|c|}{ Poland $(n=354)$} & \multicolumn{3}{|c|}{ Germany $(n=2 \mid 0)$} \\
\hline & $\begin{array}{l}\text { General } \\
\text { Mean } \pm \\
\text { SD, Me }\end{array}$ & $\begin{array}{l}\text { Patients Attended at } \\
\text { Therapeutic Education } \\
\text { Programs Against } \\
\text { Obesity (\%) }\end{array}$ & $\begin{array}{c}\text { Patients Not } \\
\text { Attended at } \\
\text { Education } \\
\text { Programs Against } \\
\text { Obesity (\%) }\end{array}$ & $\begin{array}{l}\text { General } \\
\text { Mean } \pm \\
\text { SD, Me }\end{array}$ & $\begin{array}{l}\text { Patients Attended } \\
\text { at Education } \\
\text { Programs Against } \\
\text { Obesity (\%) }\end{array}$ & $\begin{array}{c}\text { Patients Not } \\
\text { Attended at } \\
\text { Education } \\
\text { Programs Against } \\
\text { Obesity (\%) }\end{array}$ \\
\hline Poor & \multirow{3}{*}{$\begin{array}{l}19.17 \pm \\
6.59,19\end{array}$} & 16.00 & $100.00 p<0.000 I^{\#}$ & \multirow{3}{*}{$\begin{array}{c}22.01 \pm \\
4.68,22 \\
p<0.0001 *\end{array}$} & 66.67 & $100.00 p<0.0001^{\#}$ \\
\hline Average & & 84.00 & $0.00 p<0.000 I^{\#}$ & & 23.08 & $0.00 p<0.000 I^{\#}$ \\
\hline Good & & No observed & No observed & & 10.26 & $0.00 p<0.000 I^{\#}$ \\
\hline
\end{tabular}

Notes: *Statistically significant difference: Germany versus Poland for $\mathrm{p}<0.05$, " Statistically significant difference: Patients attended at education programs against obesity versus patients not attended at education program against obesity.

Abbreviations: SD, standard deviation; Me, median.

Table 3 The Influence of Obesity-Related Knowledge on Illness Perception Among Obese Patients from Poland and Germany ( $\mathrm{n}=564)$

\begin{tabular}{|c|c|c|c|c|}
\hline \multirow{3}{*}{$\begin{array}{l}\text { Level of } \\
\text { Knowledge }\end{array}$} & \multicolumn{2}{|r|}{ Poland $(n=354)$} & \multicolumn{2}{|r|}{ Germany $(n=2 \mid 0)$} \\
\hline & \multicolumn{2}{|r|}{ Illness Perception } & \multicolumn{2}{|r|}{ Illness Perception } \\
\hline & $\begin{array}{c}\text { General } \\
\text { Mean } \pm \text { SD, } \\
\text { Me }\end{array}$ & $\begin{array}{l}\text { Illness Perception Depends on Level of } \\
\text { Knowledge Mean } \pm \text { SD, Me }\end{array}$ & $\begin{array}{l}\text { General Mean } \\
\quad \pm \text { SD, Me }\end{array}$ & $\begin{array}{l}\text { Illness Perception Depends on Level of } \\
\text { Knowledge Mean } \pm \text { SD, Me }\end{array}$ \\
\hline Poor & \multirow{3}{*}{$\begin{array}{c}43.33 \pm 12.17 \\
44\end{array}$} & $43.21 \pm 11.64,40(n=333)$ & \multirow{3}{*}{$\begin{array}{l}37.98 \pm 17.23 \\
36 p<0.000 I^{*}\end{array}$} & $35.91 \pm 16.44,34(n=197)$ \\
\hline Average & & $48.53 \pm 12.23,46(n=21) p<0.000 I^{\#}$ & & $38.9 I \pm 18.46,35(n=9) p<0.000 I^{\#}$ \\
\hline Good & & No observed $(n=0)$ & & $41.11 \pm 8.33,37(n=4) p=0.0006^{\#}$ \\
\hline
\end{tabular}

Notes: *Statistically significant difference: Germany versus Poland for $\mathrm{p}<0.05$, ${ }^{\#}$ Statistically significant difference to the poor level of knowledge.

Abbreviations: SD, standard deviation; Me, median.

increased as the patient's understanding of obesity improved. In the group of obese Polish patients with an average level of obesity knowledge, the illness perception level was significantly higher than in the group of participants with a low level of knowledge $(48.53 \pm 11.64$ vs $43.21 \pm 12.23$, $\mathrm{p}<0.0001)$. Similarly, in the group of obese patients from Germany, the lowest level of disease perception was recorded in people with low knowledge of obesity, and the highest level of disease perception was observed in people with high knowledge of obesity (35.91 \pm 16.44 vs $41.11 \pm$ 8.33, $\mathrm{p}=0.0006$ ).

On the basis of the conducted research, significant differences were found between the level of disease perception and the body mass index for respondents in both the Polish and German groups. In the whole study group, the highest illness perception level was observed for patients with class III obesity (49.96 $\pm 10.73 \mathrm{PL}, 44.07 \pm 13.96 \mathrm{DE})$ and the lowest illness perception level was observed for patients with class I obesity (40.15 $\pm 11.26 \mathrm{PL}, 32.37 \pm 25.85 \mathrm{DE})$.

\section{Identification of Sociodemographic and Clinical Factors Influencing the Levels of Obesity Knowledge}

The performed multiple regression analysis for confounders influencing the level of obesity knowledge in both groups of subjects found that this level was associated with the patient's education, patient's perception of the illness, age and the number of healthcare professionals involved in the patient's treatment process $(\mathrm{p}<0.05)$ (Table 4$)$. The highest level of knowledge about obesity was possessed by older patients with higher education, a higher level of perception of obesity, 
Table 4 Multiple Regression Analysis for the Level of Knowledge Regarding Obesity $(n=564)$

\begin{tabular}{|c|c|c|c|c|c|}
\hline Variable & Coeff. & Std. Err. & $\begin{array}{l}\text { Standarized } \\
\text { Coeff. }\end{array}$ & $t$ & p-value \\
\hline \multicolumn{6}{|l|}{ Gender } \\
\hline Female & \multicolumn{5}{|c|}{$\mathrm{I} .0 \rightarrow(\mathrm{ref})$} \\
\hline Male & -0.62 & 0.51 & -0.02 & -1.21 & 0.227 \\
\hline Age & 0.07 & 0.01 & 0.20 & 4.65 & 0.000 \\
\hline Duration of Obesity & 0.04 & 0.02 & 0.09 & 1.79 & 0.079 \\
\hline \multicolumn{6}{|l|}{ BMI } \\
\hline I degree of obesity $\left(\mathrm{BMI} \geq 30-34.9 \mathrm{~kg} / \mathrm{m}^{2}\right.$ ) & \multicolumn{5}{|c|}{$\mathrm{I} .0 \rightarrow(\mathrm{ref})$} \\
\hline II degree of obesity (BMI $\geq 35-39.9 \mathrm{~kg} / \mathrm{m}^{2}$ ) & 1.87 & 1.24 & 0.15 & 1.51 & 0.132 \\
\hline III degree of obesity (BMI $\geq 40 \mathrm{~kg} / \mathrm{m}^{2}$ ) & 2.32 & 1.23 & 0.21 & 1.89 & 0.060 \\
\hline \multicolumn{6}{|l|}{ Education } \\
\hline Primary & \multicolumn{5}{|c|}{$\mathrm{I} .0 \rightarrow(\mathrm{ref})$} \\
\hline Vocational & 2.85 & 1.01 & 0.26 & 2.80 & 0.005 \\
\hline Secondary & 4.08 & 1.16 & 0.23 & 3.50 & 0.001 \\
\hline Higher & 4.58 & 1.06 & 0.39 & 4.33 & 0.000 \\
\hline \multicolumn{6}{|l|}{ Financial Situation } \\
\hline Definitely good (income per month:> 3000 EUR) & \multicolumn{5}{|c|}{$\mathrm{I} .0 \rightarrow(\mathrm{ref})$} \\
\hline Good (income per month: 200I-3000 EUR) & 0.09 & 0.66 & 0.00 & 0.15 & 0.885 \\
\hline Average (income per month: 100I-2000 EUR) & -1.69 & 0.68 & -0.15 & -2.48 & 0.014 \\
\hline Bad (income per month: 500-1000 EUR) & -2.17 & 0.89 & -0.13 & -2.42 & 0.016 \\
\hline Definitely bad (income per month: <500 EUR) & 0.28 & 2.02 & 0.00 & 0.14 & 0.89 \\
\hline IIIness Perception: & 0.05 & 0.01 & 0.14 & 3.26 & 0.001 \\
\hline $\begin{array}{l}\text { Number of Healthcare Professionals Involved in } \\
\text { the Patient's Treatment Process }\end{array}$ & 1.07 & 0.33 & 0.13 & 3.18 & 0.002 \\
\hline
\end{tabular}

and patients treated in specialized obesity treatment centers (where the obesity treatment process was involved: specialist doctors, nutritionists, physiotherapists, and psychologists). Obesity-related knowledge showed no significant dependence on body mass index, gender, duration of obesity nor material situation.

\section{Discussion}

The results of the performed study are innovative as they present one of the first international research reports in scientific literature within the scope of illness knowledge and perception among obese individuals treated in developed EU countries.

In the conducted study, the adopted scoring system reflects patients' knowledge of obesity. A scoring system was adopted, wherein scores of 23-28, 29-37, 38-46 were respectively attributed to low, average and high levels of obesity knowledge. The results of studies conducted in Poland and Germany indicate that the level of patient knowledge within the scope of obesity prevention, treatment methods, and complications is insufficient. The low 
level of obesity knowledge had the majority of the surveyed patients both in Poland and Germany (94.07\% PL vs 93.81\% DE, $\mathrm{p}=0.683$ ). Moreover, $5.93 \%$ of the Polish participants and $4.29 \%$ of the German ones had an average level of knowledge in obesity. Only $1.90 \%$ of the patients from Germany showed a high level of awareness in prevention, treatment methods, and health consequences of obesity. Nonetheless, Polish patients had a significantly lower general obesity knowledge level than their Polish counterparts $(19.17 \pm 6.59$ - PL vs $22.01 \pm 4.68$ - DE, $p<0.0001)$. The results obtained are consistent with those of other authors. Research carried out by $\mathrm{Swift}^{20}$ on a population of 104 obese adults from the UK also demonstrated low levels of knowledge regarding obesity's health risk, despite the patients' high-risk status. In the opinion by Swift et al. "health education is required to facilitate informed choices and support the use of cognitive approaches educating patients on the health and social/aesthetic consequences of obesity". Wyleżoł et $\mathrm{al}^{21}$ assessed the knowledge level within the scope of treatment methods and the most common complications of obesity across the entire Polish population. The authors observed a non-uniform level within the measures mentioned above in the studied population. Of the respondents, $91.00 \%$ were aware of the most common complications arising from an ineffectively treated obesity, whereas only $39.80 \%$ of the surveyed Poles knew about treating obesity. Nevertheless, interesting results come from a study by Winston et al, ${ }^{11}$ which aimed to measure knowledge of the health consequences of obesity among overweight/obese black and Hispanic adults. The majority of participants were knowledgeable of the risk of hypertension (94\%), diabetes (96\%), high cholesterol (91\%), joint pains/arthritis (89\%) and sleep apnea (89\%) associated with obesity, except for knowledge of the risk of breast cancer (only $53 \%$ of women).

Obesity most often contributes to the development of insulin resistance. ${ }^{22}$ In the present study, type 2 diabetes was confirmed in $27.11 \%$ of the Polish respondents and $28.57 \%$ of the German ones. Due to the high prevalence of obesity among people with diabetes, increased efforts are needed to develop and implement educational programs that focus on lifestyle changes. A study conducted by Obirikorang et $\mathrm{al}^{23}$ revealed that almost three-fourths (72\%) of obese participants with newly diagnosed type 2 diabetes had sufficient knowledge concerning the basic concept of obesity. In addition, nearly all of the patients (98.6\%) knew a method of weight measurement, but surprisingly only $4.2 \%$ of them were aware of what the ideal body weight is. Education is needed to enable individuals to comprehend the less apparent relationship between obesity and health. Lack of obesity-related knowledge is likely to compromise patients' abilities to make informed choices about their health. ${ }^{20,24}$ Disease-related knowledge is very important both for individual patients and for public health. ${ }^{25}$ It can improve treatment compliance and satisfaction, and reduce treatment costs. ${ }^{26}$ Obtaining appropriate disease-related knowledge could enable patients to effectively cope with themselves before they visit a doctor. ${ }^{27}$ The study previously conducted by the authors of the present research showed that appropriate knowledge about arterial hypertension impacts medication adherence and healthy lifestyle behaviors and improves hypertension treatment efficacy. ${ }^{28}$

Research to date indicate the need for health education and intervention program to increase health awareness and preventive practices against obesity. To the authors' knowledge, this is the first qualitative study in Poland and Germany examining the impact of the organization of educational programs on the increase in the level of patients' awareness of the health risks associated with obesity. The obtained results confirmed that the participation of patients in the educational program significantly improved their level of knowledge. Patients from Germany were significantly more likely to participate in educational programs on obesity prevention and effective treatment methods. An obesity clinic in Germany which was part of that research initiated a program called "Obesity Balance" of its own accord 20 "Obesity Balance" is a 6-month obesity therapy program, made up of different modules, dedicated to patients with a BMI $\geq 40 \mathrm{~kg} / \mathrm{m}^{2}$ or $\geq 35 \mathrm{~kg} / \mathrm{m}^{2}$ with comorbidities. "Obesity Balance" includes modules such as nutrition therapy (6 meetings), movement therapy (12 sessions), and psychoeducation (6 meetings). A doctor oversees the program. Specialists from various fields involved with the program are constantly in touch with one another. ${ }^{29}$ WHO has identified patient education and counseling as leading obesity intervention strategies as a direct approach and an adjunct to medical and surgical methods. Many studies clearly showed that medical professionals who care for obese individuals feel obligated to emphasize the health consequences of excessive body mass. ${ }^{30,31}$ In many countries, health care professionals' duty to educate obese patients on the methods of treatment and health risks associated with obesity is clearly outlined in The Management Obesity Care Pathway. ${ }^{32}$ 
The present study revealed that the level of obesity-related knowledge was associated with patient education, patient participation in therapeutic educational programs, patient perception of the illness, age and the number of healthcare professionals involved in the patients' treatment process. This study represents the first reliable compendium of scientific knowledge on identifying multiple sociodemographic and clinical factors significantly affecting patients' obesity knowledge. Research carried out by Winston ${ }^{11}$ has shown that obesity risk knowledge was not associated with past weight loss. Winston et $\mathrm{al}^{11}$ claimed that being aware of health risks helps initiate the weight loss process, although it does not indicate which patient would be successful in reducing weight. The study showed that the risk knowledge score was strongly associated with racial/ethnic factors, age, and gender. The present study and this mentioned above revealed that the most important factors contributing to patient obesity-related knowledge are patient participation in a therapeutic educational program and involvement of health care professionals in the patient education process. Increasing the number of healthcare professionals involved in treating patients increases the patient's chances of receiving health advice.

The performed study has shown that the level of illness perception was significantly higher for obese patients from Poland as compared to obese German participants. This means that Polish patients felt more threatened by the illness than German ones. The level of illness perception was associated with patient's obesity-related knowledge and body mass index. Patient awareness of health risks associated with excess body weight gives rise to anxiety associated with the loss or acute deterioration of health. A lower level of illness perception among obese patients from Germany than patients from Poland may stem from the fact that there are support groups for obese patients in German obesity treatment centers where the study was conducted. The "Obesity Balance" therapeutic program, implemented at the Charite hospital, also includes psychoeducation on changing patients' behavior and learning to cope with various emotional situations. ${ }^{29}$ According to the Health Belief Model, illness perception is a crucial predictor of health behavior change. Based on this model, the development of tailored behavior change strategies requires understanding patients' perceived risk of disease. ${ }^{11,12}$ Studies to date have shown that the number of weight loss attempts increases together with an increase in illness perception. ${ }^{9,10}$

However, our study has some limitations. The most important limitation is the fact that to assess the obesity-related knowledge, a validated, custom-made questionnaire meeting the research hypotheses was used. The questionnaire was developed following a standardized protocol that consisted of literature review, focused group discussions, and expert opinion. Nevertheless, independent Cronbach's $\alpha$ was 0.82 and 0.84 for the total score of the German and Polish versions of the questionnaire, respectively, indicating good internal consistency. Another limitation of the study is a lack of homogeneity of the study group's gender. Women predominated in both groups of respondents, which is most probably caused by the fact that more women than men tend to undergo weight loss surgery and enter any type of obesity treatment in general. ${ }^{33}$ However, this paper is a reliable and comprehensive source of knowledge regarding the impact of health policy on patients' awareness of the risks associated with obesity. Therefore, it can meet the extensive information needs of health care decision-makers and the broader medical community (including doctors, pharmacists, nutritionists, physiotherapists, and psychologists).

\section{Conclusions}

In conclusion, the level of obesity-related knowledge among both Polish and German patients was unsatisfactory. Obesity-related knowledge was associated with patient participation in therapeutic, educational programs, patients' perception of the illness, age, and the number of healthcare professionals involved in a patient's treatment process.

This study suggests that health education is required to facilitate informed choices and support the use of cognitive approaches educating patients on the health consequences of obesity. The research provides a scientific basis for health care decision-makers in Poland about the need to increase the number of professional educational programs for patients organized by health care in proper nutrition, treatment methods, prevention, and complications of obesity. In Germany, existing educational programs should be improved to increase patient awareness.

\section{Abbreviations}

EU, European Union; WHO, World Health Organization; B-IPQ, Brief Illness Perception Questionnaire; MMK (in German: Multimodales Therapiekonzept; in English: Concept of Multimodal Therapy); AOK (in German: Allgemeine 
Ortskrankenkasse; in English: General regional health insurance); Me, median; SD, standard deviation; PL, Poland; DE, Germany.

\section{Data Sharing Statement}

The dataset generated and analysed in this study is not publicly available but may be obtained from the corresponding author upon a reasonable request.

\section{Ethics Approval}

The authors assert that all procedures contributing to this work comply with the ethical standards of the relevant national and institutional committees on human experimentation and with the Helsinki Declaration of 1975, as revised in 2008. All procedures involving human patients were approved by the Ethics Committee of the Poznan University of Medical Sciences and by the ethics commission of the Charité - Universitätsmedizin Berlin, an informed, written consent to attend the study protocol was granted by all participants.

\section{Author Contributions}

All authors made a significant contribution to the work reported, whether that is in the conception, study design, execution, acquisition of data, analysis and interpretation, or in all these areas; took part in drafting, revising or critically reviewing the article; gave final approval of the version to be published; have agreed on the journal to which the article has been submitted; and agree to be accountable for all aspects of the work.

\section{Funding}

This research did not receive any specific grant from funding agencies in the public, commercial, or not-for-profit sectors.

\section{Disclosure}

The authors report no conflicts of interest for this work.

\section{References}

1. World Health Organization. Department of Nutrition and Food Safety (NFS). Available from: https://who.int/health-topics/obesity. Accessed January 12, 2022.

2. Schienkiewitz A, Mensink GBM, Kuhnert R, Lange C. Overweight and obesity among adults in Germany. J Health Monit. 2017;2:20-27.

3. OECD. Obesity update; 2017. Available from: http://www.oecd.org/health/obesity-update.htm. Accessed February 23, 2022.

4. Stepaniak U, Micek A, Waśkiewicz A, et al. Prevalence of general and abdominal obesity and overweight among adults in Poland. Pol Arch Med Wewn. 2016;126(9):662-671. doi:10.20452/pamw.3499

5. National institute for health and clinical excellence: obesity: the prevention, identification, assessment and management of overweight and obesity in adults and children, NICE. Available from: https://www.nice.org.uk/guidance/cg43. Accessed October 14, 2020.

6. World Health Organisation. Obesity and overweight, World Health Organisation. Available from: http://www.who.int/mediacentre/factsheets/fs311/ en/. Accessed October 14, 2020.

7. Walsh K, Grech C, Hill K. Health advice and education given to overweight patients by primary care doctors and nurses: a scoping literature review. Prev Med Rep. 2019;14:100812. doi:10.1016/j.pmedr.2019.01.016

8. Sheeran P, Abraham C. The health belief model. In: Conner M, Norman P, editors. Predicting Health Behaviour: Research and Practice with Social Cognition Models. Buckingham, UK: Open University Press; 1996:385.

9. Mainous AG, Diaz VA, Koopman RJ, Everett CJ. Having a regular physician and attempted weightloss after screening for hypertension or hypercholesterolemia. Int J Obes. 2005;29(2):223-227. doi:10.1038/sj.ijo.0802863

10. Gorin AA, Phelan S, Hill JO, Wing RR. Medical triggers are associated with better short and long-term weight loss outcomes. Prev Med. 2004;39 (3):612-616. doi:10.1016/j.ypmed.2004.02.026

11. Winston GJ, Caesar-Phillips E, Peterson JC, et al. Knowledge of the health consequences of obesity among overweight/obese Black and Hispanic adults. Patient Educ Couns. 2014;94(1):123-127. doi:10.1016/j.pec.2013.09.022

12. Prochaska JO, Redding CA, Evers KE. The trans theoretical model and stages of change. In: Glanz K, Rimer BK, Lewis FM, editors. Health Behavior and Health Education: Theory, Research, and Practice. San Francisco, CA: John Wiley \& Sons, Inc; 2002:592.

13. Sisnowski J, Handsleyb E, Streeta JM. Regulatory approaches to obesity prevention: a systematic overview of current laws addressing diet-related risk factors in the European Union and the United States. Health Policy. 2015;119:720-731. doi:10.1016/j.healthpol.2015.04.013

14. Ukudeyeva A, Ramirez LR, Rivera-Castro A, Faiz M, Espejo M, Kanna B. 2460 qualitative study of obesity risk perception, knowledge, and behavior among Hispanic taxi drivers in New York. J Clin Transl Sci. 2018;2:72-73.

15. Consedine NS, Magai C, Conway F, Neugut AI. Obesity and awareness of obesity as risk factors for breast cancer in six ethnic groups. Obes Res. 2004;12(10):1680-1689. doi:10.1038/oby.2004.208 
16. Taber KS. The use of Cronbach's alpha when developing and reporting research instruments in science education. Res Sci Educ. 2018;48:1273-1296. doi:10.1007/s11165-016-9602-2

17. Kossakowska MM, Stefaniak TF. Psychometric properties for the Polish version of the Brief Illness Perception Questionnaire (Brief IPQ). Health psychology report. 2017;5(1):67-83.

18. Valenta S, Geest SD, Fierz K, et al. Perception of late effects among long-term survivors after haematopoietic stem cell transplantation: Descriptive analysis and validation of the Brief Illness Perception Questionnaire. A sub-study of the PROVIVO study. Eur J Oncol Nurs. 2017;27:17-27. doi:10.1016/j.ejon.2017.01.003

19. Broadbent E, Petrie KJ, Main J, Weinman J. The brief illness perception questionnaire. J Psychosom Res. 2006;60(6):631-637. doi:10.1016/j. jpsychores.2005.10.020

20. Swift JA, Glazebrook C, Anness A, Goddard R. Obesity-related knowledge and beliefs in obese adults attending a specialist weight-management service: implications for weight loss over 1 year. Patient Educ Couns. 2009;74(1):70-76. doi:10.1016/j.pec.2008.07.045

21. Wyleżoł H, Omelańczuk I, Radziszewski M, Kaczmarska-Turek D, Bednarczuk T. An assessment of the knowledge concerning obesity among the adult Polish population — a preliminary study. Forum Zaburzen Metabolicznych. 2017;8(1):36-45.

22. Hardy OT, Czech MP, Corvera S. What causes the insulin resistance underlying obesity? Curr Opin Endocrinol Diabetes Obes. $2012 ; 19(2): 81-87$. doi:10.1097/MED.0b013e3283514e13

23. Obirikorang Y, Obirikorang C, Anto EO, et al. Knowledge and lifestyle-associated prevalence of obesity among newly diagnosed type II diabetes mellitus patients attending diabetic clinic at Komfo Anokye Teaching Hospital, Kumasi, Ghana: a hospital-based cross-sectional study. J Diabetes Res. 2016;2016:1-10. doi:10.1155/2016/9759241

24. Petrovici DA, Ritson C. Factors influencing consumer dietary health preventative behaviours. BMC Public Health. 2006;6(1):222. doi:10.1186/ 1471-2458-6-222

25. Yoo YS, Cho OH, Cha KS. Disease-related knowledge and information needs among inflammatory bowel disease patients in Korea. Gastroenterol Nurs. 2015;38(6):455-463. doi:10.1097/sga.0000000000000063

26. Molenaar S, Sprangers MA, Rutgers EJ, et al. Decision support for patients with early-stage breast cancer: effects of an interactive breast cancer CDROM on treatment decision, satisfaction, and quality of life. J Clin Oncol. 2001;19(6):1676-1687. doi:10.1200/jco.2001.19.6.1676

27. Casellas F, Fontanet G, Borruel N, et al. The opinion of patients with inflammatory bowel disease on healthcare received. Rev Esp Enferm Dig. 2004;96(3):174-184. doi:10.4321/s1130-01082004000300003

28. Paczkowska A, Hoffmann K, Kus K, et al. Impact of patient knowledge on hypertension treatment adherence and efficacy: a single-centre study in Poland. Int J Med Sci. 2021;18(3):852-860. doi:10.7150/ijms.48139

29. Charité - Universitätsmedizin Berlin. Multimodales Therapiekonzept "ObesityBalance". Available from: https://interdisziplinaeresadipositaszentrum.charite.de/fuer_patienten/therapie/konservativ/multimodal. Accessed February 23, 2022. German.

30. Kan K, Tsai WD. Obesity and risk knowledge. J Health Econ. 2004;23(5):907-934. doi:10.1016/j.jhealeco.2003.12.006

31. Swift JA, Sheard C, Rutherford M. Trainee health care professionals' knowledge of the health risks associated with obesity. J Hum Nutr Diet. 2007;20(6):599-604. doi:10.1111/j.1365-277X.2007.00826.x

32. Department of Health. Care pathway for the management of overweight and obesity; 2006. Available from: http://www.dh.gov.uk/assetRoot/04/13/ 45/60/04134560.pdf. Accessed February 23, 2022.

33. Snyder B, Nguyen A, Scarbourough T, Yu S, Wilson E. Comparison of those who succeed in losing significant excessive weight after bariatric surgery and those who fail. Surg Endosc. 2009;23(10):2302-2306. doi:10.1007/s00464-008-0322-1

Diabetes, Metabolic Syndrome and Obesity: Targets and Therapy

\section{Publish your work in this journal}

Diabetes, Metabolic Syndrome and Obesity: Targets and Therapy is an international, peer-reviewed open-access journal committed to the rapid publication of the latest laboratory and clinical findings in the fields of diabetes, metabolic syndrome and obesity research. Original research, review, case reports, hypothesis formation, expert opinion and commentaries are all considered for publication. The manuscript management system is completely online and includes a very quick and fair peer-review system, which is all easy to use. Visit http://www.dovepress. com/testimonials.php to read real quotes from published authors.

Submit your manuscript here: https://www.dovepress.com/diabetes-metabolic-syndrome-and-obesity-targets-and-therapy-journal 